\title{
MARKETING VERDE DE PRODUTOS FLORESTAIS: TEORIA E PRÁTICA
}

\author{
Carlos Alberto Marçal Gonzaga* \\ * Bacharel em Administração, Doutorando em Eng. Florestal, UFPR, Depto. de Administração, UNICENTRO - artgonzaga@yahoo.com
}

Recebido para publicação: 09/06/2005 - Aceito para publicação: 31/08/2005

\begin{abstract}
Resumo
Marketing verde de produtos florestais: teoria e prática. $\mathrm{O}$ artigo "Marketing verde de produtos florestais: teoria e prática" apresenta um estudo sobre as características e atributos do marketing verde, exemplificado por um estudo de caso do marketing de produtos madeireiros no Canadá, onde pesquisas de avaliação do Ciclo de Vida de produtos utilizados em edificações mostraram que o aço e o concreto embutem $26 \%$ e $57 \%$ mais energia; emitem $34 \%$ e $81 \%$ mais gases de efeito estufa; liberam $24 \%$ e $47 \%$ mais poluentes no ar; despejam 4 e 3,5 vezes mais poluentes na água; usam $11 \%$ e $81 \%$ mais matéria prima em peso; e produzem $8 \%$ e $23 \%$ mais dejetos sólidos, respectivamente, do que a madeira. Embora a estratégia de diferenciação ambiental possa ser considerada um caso particular de marketing de diferenciação de produtos, o tema requer uma abordagem que considere, além dos aspectos econômicos, as demandas sócio-ambientais que afetam as regulamentações do mercado, a percepção dos consumidores e a responsabilidade social das organizações. O marketing verde incorpora uma dimensão de educação para o consumo ambiental sustentável, que complementa o desenvolvimento de produtos menos poluentes, a contabilização dos custos ambientais e a implementação de uma ética ambiental.

Palavras-chave: Marketing ambiental; diferenciação ambiental; mercado madeireiro.
\end{abstract}

\begin{abstract}
Green marketing of forest products: theory and application. The article "Green marketing of forest products: theory and application" presents a study on green marketing characteristics, and shows the case of Canadian wood marketing, where researches on building product's Life-Cycle Assessment indicates that both the steel and concrete products, due to substitute wood products, embody and consume $12 \%$ and $20 \%$ more energy, emit $15 \%$ and $29 \%$ more greenhouse gases, release $10 \%$ and $12 \%$ more air pollution, discharge 3 and 2.25 times more water pollution, use $7 \%$ and $50 \%$ more resources from a weighted resource use perspective, and produce $6 \%$ and $16 \%$ more solid wastes, respectively. While the strategy for products' environmental differentiation is a special case in marketing of product differentiation, the particular approach for the issue requires considerations beyond economics. It includes social environmental demands that affect market regulations, consumers' perception and social responsibility of organizations. The green marketing incorporates a dimension of education for sustainable consumption added to the aspects of products' research and development, environmental costs accounting and implementation of an environmental ethics.

Keywords: Environmental marketing; environmental differentiation; wood market.
\end{abstract}

\section{INTRODUÇÃO}

De modo geral, o marketing de diferenciação de produtos é centrado na criação ou enfatização de uma característica benéfica em um produto que seja percebida como valor significativo pelos consumidores e os motive a optar pelo consumo de tal produto. A percepção de valor, em última instância, é baseada na equação entre custos e benefícios associados ao consumo do produto, incluindo-se os custos não-financeiros e os benefícios intangíveis. Para haver produção comercial de um produto é necessário motivar uma quantidade suficiente de indivíduos dispostos a pagar o preço mínimo que justifique sua comercialização.

A diferenciação ambiental em marketing, também denominada de marketing verde, marketing

FLORESTA, Curitiba, PR, v. 35, n. 2, mai./ago. 2005. 
ambiental, marketing ecológico e ecomarketing, é um caso especial de marketing de diferenciação de produtos. O termo refere-se aos instrumentos mercadológicos utilizados para explorar os benefícios ambientais proporcionados por um produto. Os benefícios ambientais mais valorizados são aqueles que contribuem para a sustentabilidade dos ecossistemas do planeta. Como a sustentabilidade dos recursos naturais necessários para a produção de bens destinados ao consumo humano implica mudanças quantitativas e qualitativas da oferta e da demanda, a utilização do marketing verde pressupõe a idéia de que seja possível criar riquezas com a diminuição de impactos ambientais negativos e a promoção de mudanças sociais que afetem os hábitos de consumo no mercado.

Os novos conhecimentos científicos sobre o meio ambiente, o aumento das demandas sociais ambientalistas e o desenvolvimento de novas tecnologias afetam as regulamentações formais do mercado e a organização da produção, que tendem a adequar-se às transformações nos cenários comerciais. $\mathrm{O}$ crescimento demográfico exponencial e a globalização da economia multiplicaram os efeitos problemáticos da degradação ambiental, porque a busca de realização do ideal de desenvolvimento econômico para um número crescente de nações acelerou o consumo e a depleção dos recursos naturais disponíveis e aumentou exacerbadamente o volume de resíduos produzidos. Os recursos naturais não renováveis tendem naturalmente à escassez, mas mesmo os recursos naturais renováveis também tendem à escassez se a gestão da exploração não for ecologicamente sustentável. Por isso, a depleção dos recursos naturais e a redução da qualidade ambiental incrementam o custo social e financeiro do desenvolvimento econômico, embora os custos ambientais não sejam incluídos nos balanços contábeis, e reduzem as possibilidades de desenvolvimento sustentável.

Diante dos problemas ambientais se agravando e com maior nível de informação por parte das pessoas, cresce a demanda social por políticas governamentais que restrinjam o acesso a fontes de recursos naturais ou que limitem o uso de tais recursos. Junto com a demanda pelo uso sustentável do meio ambiente tende a crescer a vigilância pelos valores éticos das organizações empresariais. No entanto, o desenvolvimento de tecnologias adequadas para maximizar o aproveitamento dos recursos naturais e as medidas administrativas adequadas aos novos cenários produtivos exige investimentos que obedecem a "Lei dos Rendimentos Decrescentes", segundo a qual, mantido fixo um dos recursos produtivos, os investimentos nos demais recursos não propiciarão aumentos proporcionais na capacidade produtiva, tornando-se decrescentes ou nulos em um transcurso de tempo. Custos maiores e rendimentos decrescentes exigem estratégias mercadológicas adequadas para a manutenção da competitividade diante dos novos padrões de acumulação e a continuidade da organização no mercado.

O desafio posto pelo mercado aos setores de produção de bens e serviços é o de buscar as soluções de gestão que sejam economicamente adequadas, socialmente aceitáveis e ambientalmente sustentáveis. Do ponto de vista estratégico para a área de marketing, as questões centrais são: 1) Qual o mix de produtos a ser ofertado que atenda as demandas de desempenho, preço e benefícios ambientais? e 2) De que forma apresentar isso ao consumidor para que ele decida consumir? A realização de pesquisas de mercado para conhecer a disposição dos consumidores em pagar por produtos "verdes" e o desenvolvimento de produtos que agreguem valor ambiental para os consumidores, permitindo economia de escala produtiva, parecem ser as etapas básicas para as soluções administrativas economicamente mais racionais.

No setor de produtos madeireiros, os benefícios ambientais constituem-se em fator primordial de vantagem competitiva em relação aos produtos substitutos (concreto, aço, plástico, etc). Mas, como na percepção popular o uso da madeira está associado ao desmatamento e à desertificação, contrapor-se à concorrência dos produtos substitutos exige mais do que melhorar o desempenho dos produtos com investimento em desenvolvimento tecnológico. É necessário saber criar valor de mercado para tais produtos e saber capturar o valor criado para propiciar rendimento aos investidores. Este estudo tem como objetivo investigar, através de revisão bibliográfica, a teoria sobre a diferenciação ambiental em marketing, o marketing verde, e apresentar um estudo de caso sobre o setor madeireiro do Canadá, que se constitui num exemplo que está em concordância com as proposições teóricas estudadas.

\section{Gestão ambiental}

A inclusão da proteção ambiental entre os objetivos da administração remonta à administração da qualidade total para o ambiente, derivada da Total Quality Management (TQM), desenvolvida por W. E. Deming (1950). A gestão ambiental, portanto, pode ser considerada como a busca da excelência na 
gestão da qualidade total (Saunders; McGovern, 1997). Tal abordagem amplia o escopo dos conceitos de administração porque busca o contínuo aprimoramento dos processos empresariais para melhor atender as necessidades e expectativas do mercado e ao mesmo tempo reduzir o desperdício de recursos.

De acordo com Dyllik, citado por Callenbach et al. (1999), inovação, cooperação e comunicação constituem-se nos três elementos-chave para as estratégias da administração com consciência ecológica. As inovações que reduzem o uso de recursos, por um lado, diminuem o impacto ambiental e os custos das operações empresariais, e, por outro, adicionam benefícios ambientais aos produtos que, se valorizados pelos consumidores, podem representar vantagem competitiva e gerar renda adicional durante a comercialização. Por sua vez, Edmunds e Letey (1975) enumeram quatro elementos que direcionam as tendências da gestão ambiental. O primeiro se refere ao estabelecimento de políticas públicas regulamentando o uso da terra e dos recursos naturais; o segundo se refere ao uso de mecanismos de mercado e de estruturação dos preços para o uso dos recursos naturais; o terceiro se refere às preferências das organizações e da comunidade política; e o quarto se refere às preferências individuais e critérios decisórios dos consumidores.

As organizações mercantis podem ser consideradas como instituições sociopolíticas que interagem com seu meio ambiente. Trata-se de um conceito voltado à dimensão social das atividades produtivas e sua função de manter a qualidade de vida na sociedade. Devido à "liberdade que a sociedade concede" às empresas para existirem, elas devem retribuir com a responsabilidade social de suas atividades como pagamento por essa liberdade (Donaire, 1995). Sendo assim, a gestão ambiental deve orientar-se para a preservação da saúde e da biodiversidade, com foco no balanço entre a satisfação das necessidades econômicas no curto prazo e o equilíbrio ecológico no longo prazo. Tal idéia também é compartilhada por Schmidheiny (1992), que, na busca por diretrizes para a eficiência ecológica, conclui que isso requer concepções, metas e práticas empresariais consoantes à exploração sustentada dos recursos naturais, considerando as necessidades das pessoas no futuro, somente possível através do compartilhamento de uma nova visão de mundo e de uma ética coletiva baseadas na igualdade de oportunidades entre pessoas, entre nações e entre as gerações presentes e as futuras.

Um dos grandes problemas macroeconômicos resultantes da exploração de matéria-prima e industrialização de produtos em qualquer setor econômico está na geração de resíduos e desperdício de recursos. Para o Business Council for Sustainable Development (BCSD - Conselho Empresarial para o Desenvolvimento Sustentável), os limites para o crescimento econômico estão menos na escassez de recursos, conforme previsto pelo Clube de Roma em 1972 (The Limits to Growth), do que na escassez de sistemas para absorver com segurança o lixo gerado pela humanidade (Schmidheiny, 1992). Por isso, no longo prazo, o objetivo da gestão ambiental é passar de "controle da poluição" para "prevenção da poluição",

Como a poluição significa recursos desperdiçados no sistema produtivo, além de redução da qualidade ambiental, a principal solução para os problemas ambientais apresentada pelo BCSD é atribuir um valor à poluição e cobrar das organizações pelos danos que causam ao meio ambiente. Tal cobrança é a introdução de um valor de mercado aos bens públicos e aos custos ambientais e tem o objetivo de pressionar as empresas a poluírem menos e a desenvolverem tecnologias mais eficientes. Como tais custos provavelmente serão repassados aos preços cobrados do consumidor final, preços maiores para produtos que poluem mais sinalizam aos consumidores para procurarem produtos substitutos que poluem menos.

Os custos ambientais referem-se ao custo da oferta de bens públicos, ou seja, bens aos quais todos têm direito de acesso independentemente de responsabilizar-se pelo ônus da existência. No entanto, de acordo com Reinhardt (1999, p. 39), a produção de bens públicos pode ser interessante do ponto de vista empresarial, porque, “(...) embora não se possa excluir o consumo de quem não pagou por sua produção, a intervenção governamental no mercado, mais o fenômeno da informação incompleta e outras externalidades [que determinam as imperfeições do mercado] fazem com que seja possível auferir vantagens mercadológicas com eles".

Três mecanismos básicos, segundo Schmidheiny (1992), podem ser usados para induzir as organizações a internalizarem os custos ambientais ou a limitarem os danos que causam ao meio ambiente. O primeiro se refere aos instrumentos de "comando e controle" governamental através das regulamentações restritivas; o segundo se refere à "auto-regulamentação", com a qual as organizações podem reduzir os custos de adequação, antecipando-se às regulamentações governamentais; o terceiro se 
refere aos "instrumentos econômicos", como impostos e taxas, que interferem nos preços a ponto de estimular ou desestimular comportamentos de produção e consumo.

A adoção de estratégias ambientais em marketing necessita da implementação de uma ética ambiental na organização que as utiliza, idéia defendida por vários autores (Saunders; McGovern, 1997; Ottman, 1994 e 1998; Reinhardt, 1999; Callenbach et al., 1999). Um conceito possível é de que se trata de "(...) um sistema de valores centrado na terra e não no homem, respeitando a riqueza e a diversidade de todas as formas de vida" (Callenbach et al., 1999, p. 15). Ottman (1994, p. 56) afirma que “(...) é por meio da criação de uma ética ambiental que abranja toda a empresa que estratégias de marketing podem ser executadas". De acordo ainda com Reinhardt (1999), a percepção de coerência ética da empresa em relação às questões ambientais referentes a um produto pode criar um efeito halo para seus outros produtos.

Uma mudança de valores na cultura empresarial, impulsionada pela ética ambiental e pela preocupação com o bem-estar das futuras gerações, pode ser considerada o ponto de partida para a gestão ambiental. A promoção da ética ambiental numa organização pode ser feita de várias formas, mas sempre depende, basicamente, do uso das técnicas de relações públicas, tanto para o público interno, em todos os níveis hierárquicos, quanto para a sociedade em geral (Ottman, 1994). A implantação prática da gestão ambiental constitui-se, portanto, na melhor maneira de alcançar os objetivos ambientais da sociedade e ao mesmo tempo criar atividades empresariais mais lucrativas.

Argumenta Donaire (1995) que as regulamentações formais do mercado evoluíram do paradigma de dar sustentação às condições que permitam às empresas atingir seus objetivos econômicos, para o paradigma de considerar a responsabilidade social das empresas como de importância fundamental. Sendo assim, a conquista da credibilidade e da competitividade por parte das empresas depende do uso de recursos renováveis (assegurando-se que sejam renovados), com a redução de dejetos que não possam ser usados como recursos e com iniciativas pioneiras para a superação do mero cumprimento da legislação vigente (Saunders; McGovern, 1997). Em nível global, depende também da disseminação de tecnologias e da distribuição dos bens necessários à sobrevivência das nações em mercados abertos e competitivos, com os custos ambientais incorporados aos preços (Schmidheiny, 1992). Espera-se que o compartilhamento de conhecimento e o diálogo permitam reduzir o abismo entre a responsabilidade ambiental e as necessidades econômicas.

Sob a ótica econômica, as decisões sobre meio ambiente buscam reduzir riscos futuros e aproveitar as oportunidades para aumentar o valor agregado dos bens e serviços produzidos, o que coincide com o objetivo central de qualquer atividade empresarial: criar e capturar valor. Reduzir riscos implica custos. Se prover qualidade ambiental além das exigências normativas deixa os custos superiores aos da concorrência, então, adverte Reinhardt (1999), não é economicamente lógico prover mais benefícios do que é legalmente mandatório, porque se torna mais difícil recuperar os gastos adicionais e ainda obter lucros.

\section{Marketing verde}

Segundo Polonsky (1994), o marketing verde consiste no conjunto das atividades concebidas para produzir e facilitar a comercialização de qualquer produto ou serviço com a intenção de satisfazer necessidades e desejos humanos, porém causando impacto mínimo ao meio ambiente. Envolve modificação de produtos e embalagens, bem como mudanças em processos de produção e publicidade. Sua importância se deve ao fato de as pessoas utilizarem recursos limitados para satisfazerem desejos ilimitados. É baseado no pressuposto de que os consumidores querem um meio ambiente mais limpo e estão dispostos a pagar por isso.

Jöhr (1994, p. 86) define o marketing verde como “(...) colocar os objetivos de marketing em termos ecológicos". A conseqüência é o desenvolvimento de produtos ecologicamente orientados e menos agressivos ao meio ambiente, que gastem menos energia, produzam menos resíduos, consumam menos matéria-prima, apresentem maior facilidade de manutenção, possuam embalagens mais adequadas, sejam distribuídos sem riscos e permitam descarte sem resíduos. Além disto, os serviços de assistência técnica e de orientação ao consumidor cumpririam a função de “(...) assegurar que os produtos sejam usados e descartados de forma correta" (Donaire, 1995, p. 101-102).

Embora o conceito de produto "ecológico" seja relativo a fatores como tipo de produto, tipo de mercado, cultura do consumidor, disponibilidade de informação científica, etc., os produtos aos quais se 
pode aplicar o conceito de marketing verde, de acordo com Ottman (1998), tendem a ser duráveis, nãotóxicos, feitos de materiais reciclados e com o mínimo de embalagem. Para produzi-los, são consideradas cada fase do seu ciclo de vida, incluindo questões como conservação de recursos naturais não-renováveis, eficiência energética e proteção de hábitats e de espécies ameaçadas de extinção. São produtos com vantagens ambientais óbvias para o consumidor, porque oferecem a perspectiva de mais saúde, vida mais completa e a oportunidade para transformar o mundo em um lugar melhor, o que representa uma vantagem do marketing verde sobre o marketing convencional.

O primeiro desafio mercadológico para as organizações que decidem adotar o marketing verde é o de operar com práticas ambientais adequadas sem deixar de ofertar qualidade, conveniência e preço adequado aos consumidores (Saunders; McGovern, 1997). Isso pode requerer a definição de nichos específicos de mercado para produtos ecológicos, investimento em técnicas de comunicação para ampliar o nível de informação do público quanto às características ambientais dos produtos, reforço das campanhas ambientalistas para aumentar a sensibilização dos consumidores em relação ao meio ambiente, investimento na imagem da empresa para que seja percebida como comprometida com a preservação ambiental, participação e apoio institucional em ações ambientalistas da comunidade, utilização de transporte menos poluidor, maior eficiência no uso de energia, articulação de rede de contatos e articulação para facilitar a redistribuição de materiais reutilizáveis ou recicláveis.

O segundo desafio para implantar com êxito uma estratégia de marketing verde é conseguir fazer com que as políticas ambientais organizacionais sejam valorizadas por todos os níveis hierárquicos. Para isso, a comunicação interna deve ser coerente com o planejamento estratégico e com as ações empreendidas. A habilidade para formar coalizões com formadores de opinião (crianças, governo, ambientalistas, mídia, varejistas) e a capacidade para gerenciar as etapas de marketing em colaboração com fornecedores e distribuidores tornam-se essenciais (Ottman, 1994). Às vezes, para alcançar metas ambientais estratégicas, pode ser necessário à organização pressionar fornecedores a modificar suas atividades, para que ofereçam produtos com menor impacto ambiental embutido e que minimizem o impacto de seu uso sobre o meio ambiente.

Para adotar o marketing verde, as organizações devem estar prontas para definir-se como integradas à natureza, operar holisticamente e assumir a missão de criar riquezas enquanto ajudam a promover mudanças sociais, ou seja, orientar-se por dois objetivos básicos: obter lucros e contribuir com o bem-estar da sociedade (Ottman, 1998). As questões ambientais emergentes devem ser antecipadas com soluções que antecedam a obrigatoriedade legal e excedam o mínimo exigido por lei. Atuando dessa forma, as organizações podem definir os padrões, estabelecer as regras do setor e liderar o mercado.

\section{Diferenciação ambiental de produtos}

De modo geral, o marketing de diferenciação de produtos é centrado na criação ou enfatização de uma característica benéfica em um produto que motive um número significativo de consumidores a optar pelo consumo de tal produto (Hooley; Saunders; Piercy, 2001). A característica benéfica do produto deve ser percebida pelos consumidores como um valor vantajoso em relação ao seu custo (Lovelock, 1995). Do ponto de vista da microeconomia, a diferenciação de produtos é a criação de um novo mercado, protegido por barreiras que impedem ou dificultam a entrada ou a mobilidade de concorrentes, no qual há elasticidade limitada da demanda (Reinhardt, 1999). A diferenciação ambiental de produtos é um caso especial de marketing de diferenciação de produtos.

Segundo Kotler (1997), o sucesso do marketing de diferenciação de produtos depende, basicamente, da capacidade da empresa em atender aos seguintes critérios: a) importância para um número suficiente de consumidores; b) distinção em relação à concorrência; c) superioridade em relação a outras formas de obter o mesmo benefício; d) comunicabilidade aos consumidores; e) preempção em relação a cópias e imitações; f) acessibilidade aos consumidores; g) lucratividade para os produtores. Baseado nestes sete requisitos, Reinhardt (1999) identifica três condições necessárias para a adoção dessa estratégia de marketing. A primeira é a disposição do consumidor em pagar pela qualidade ambiental - tal disposição pode estar latente e precisa ser ativada, ou pode não existir e precisa ser criada através de educação e informação adequada. A segunda condição é a disponibilização de informações confiáveis sobre o produto ou serviço e seus atributos ambientais. A terceira é a proteção das inovações contra imitações por parte dos concorrentes, para compensar os investimentos em pesquisa e desenvolvimento.

O acelerado avanço das tecnologias informacionais e a globalização, alerta Kotler (2001, p.6), 
tornam cada vez mais difícil para as empresas a manutenção da vantagem competitiva baseada na diferenciação, porque “(...) os concorrentes podem copiar rapidamente qualquer vantagem através de benchmarking, engenharia reversa e leapfrogging". Benchmarking refere-se à utilização do exemplo de outras empresas como ponto de referência para medida de resultado; leapfrogging refere-se à teoria de desenvolvimento em que se pulam estágios tecnológicos, dos mais poluentes, caros e ineficientes direto para os mais avançados e mais sustentáveis.

A diferenciação ambiental não é um atributo de produto ou serviço que substitua qualquer uma de suas utilidades básicas, ainda que o consumidor possa aceitar algum tipo de troca entre as vantagens de conveniência e preço pelas vantagens de qualidade ambiental e saúde (Ottman, 1998). À medida que cresce a importância da variável ambiental no mercado de bens, os produtos que necessitam de uso intensivo de recursos vão sendo substituídos por produtos com concepções inovadores e serviços desmaterializados (que reduzem a quantidade de matéria-prima necessária). Esses produtos permitem maior agregação de valor comercial por conta do potencial educacional e pelos valores que promovem, projetando imagem de alta qualidade (sensibilidade ambiental) tanto dos produtos quanto da organização. A "sensibilidade ambiental" e a "compatibilidade ambiental" (que se refere aos impactos de longo prazo) são consideradas por Ottman (1994 e 1998) como atributos essenciais, embora não suficientes, para o sucesso de uma estratégia de diferenciação ambiental.

Os motivos que podem pesar favoravelmente à adoção da estratégia de diferenciação ambiental são apontados por Polonsky (1994) como sendo a oportunidade contingencial de alcançar objetivos organizacionais, a obrigação moral de ser socialmente responsável, a obrigação legal de cumprir as normatizações, a necessidade de manter capacidade competitiva no mercado e a redução de custos operacionais. Os produtos concebidos com preocupações ecológicas tendem a gerar lucros se demandam menos matéria-prima e energia, se reduzem o desperdício de recursos e se ajudam a aumentar a moral e a produtividade dos trabalhadores. Isso está em acordo com a teoria de Qualidade Total, em que se considera que os custos totais da qualidade podem ser reduzidos por meio de um acréscimo dos custos de prevenção (Cordeiro, 2004). Muitas vezes, no entanto, tais vantagens só podem ser consideradas no longo prazo, porque no curto prazo tende a haver uma elevação dos custos por conta do processo de adaptação a novos procedimentos e tecnologias. Como o longo prazo só pode se concretizar se o curto prazo for administrado e superado, o aumento do custo operacional no curto prazo é repassado para o preço dos produtos, o que limita a demanda, que por sua vez inibe a oferta. Com a oferta inibida em função dos custos do pioneirismo, as empresas pioneiras nos mercados podem acrescentar um valor-prêmio ao preço dos produtos considerados ecológicos, aumentando a rentabilidade do capital investido no desenvolvimento de tais produtos. Por outro lado, a criação de nichos específicos de mercado para produtos 'verdes' também pode aumentar a participação da empresa no mercado, compensando possíveis perdas no lucro marginal sobre as inversões de capital (Reinhardt, 1999).

\section{Comportamento do consumidor}

No mercado industrial, onde a identidade de marca e a imagem institucional tendem a ser secundárias, a disposição de um cliente para pagar pela diferenciação ambiental é, geralmente, definida em função do custo total. No mercado de bens de consumo, a disposição de um consumidor para pagar pela diferenciação ambiental é limitada pela utilidade do produto, pelo sucesso ou insucesso em tentativas anteriores de diferenciação e pela sensibilidade ambiental dos consumidores. Afirma Ottman (1994, p. 14) que “(...) a percepção é a realidade" quando se trata do consumo de produtos "ecológicos", porque vários fatores psicológicos e sociológicos influenciam as decisões sobre consumo.

As questões ambientais passaram a ser percebidas como questões de qualidade de vida, estimulando o consumo com atitude de responsabilidade social no contexto mundial, de rápida divulgação dos novos conhecimentos científicos sobre as mudanças ambientais no planeta quanto a aquecimento da atmosfera, extinção de ecossistemas, etc. Na medida em que os consumidores dispõem de maior acesso a informações confiáveis, a novas tecnologias e a infra-estruturas que facilitem o consumo com responsabilidade ambiental, atitudes ambientalistas vão sendo incorporadas ao seu estilo de vida. Eventualmente, tais atitudes assumem dimensões de movimentos sociais que exigem medidas de gerenciamento de riscos ambientais por parte das organizações, como é o caso da Alberta-Pacific Forest Industries Inc., uma indústria de celulose na Província de Alberta, Canadá, formada por uma joint venture das japonesas Mitsubishi Corporation e Oji Paper Company Ltd., que, em função das manifestações 
hostis de fazendeiros, indígenas e ambientalistas contra a poluição do Rio Athabasca, eliminou o uso do gás clorine como branqueador e o substituiu pelos menos poluentes dióxido de clorine e peróxido de hidrogênio (Reinhardt, 1999).

Em geral, os consumidores são motivados pelas necessidades universais de ter controle, fazer diferença, obter informação e manter estilo de vida. Os consumidores ambientalistas são os que conscientemente buscam produtos que exercem impacto ambiental mínimo (Ottman 1998). A compra deliberada de produtos que embutem benefícios ambientais superiores parece ser determinada pela sensação de fazer algo importante pelo meio ambiente - sensação de empowerment (adquirir poder de influência). Assim, por exemplo, há preferência por produtos que apresentam perspectivas de alta qualidade, praticidade e menor risco para as crianças, desde que sejam garantidos os benefícios primários (performance, conveniência, preço e segurança). O principal fator de compra continua a ser, segundo Ottman (1994), a eficácia do produto, pois não se compra um produto para salvar o planeta, mas para beneficiar-se de sua utilidade. Uma característica importante do mercado, observa Reinhardt (1999, p. 37), é que “(...) a demanda por qualidade ambiental é elástica em relação à renda e ao nível educacional”.

A análise das preferências e da estrutura decisória dos consumidores permite identificar o que direciona a modificação da qualidade ambiental, porque as organizações são bastante sensíveis às variações marginais dos volumes de venda, em função dos custos fixos que possuem. De acordo com os modelos econômicos clássicos, assume-se que os indivíduos, agentes racionais, sempre utilizam a racionalidade para fazer escolhas que maximizem seus benefícios, mas tais modelos só se aplicam a situações em que há disponibilidade de informações sobre todas as opções disponíveis.

Nas decisões tomadas diante do fenômeno da informação incompleta, de acordo com estudos de Edmunds e Letey (1975, p. 170-171), quando os consumidores deparam-se com situações em que não sabem como otimizar os benefícios porque “(...) não dispõem dos meios de informação necessários para saber quais são as alternativas ofertadas, nem como decidir pela melhor opção", a satisfação é alcançada com a redução das aspirações a metas exeqüíveis, adotando comportamento de adaptação ao que é possível. Devido ao fenômeno da informação incompleta, as organizações empresariais podem auferir vantagem competitiva se mostrarem ao público quais são seus compromissos ambientais e sociais (Reinhardt, 1999). Por isso, é fundamental o trabalho de informação ao público por parte das empresas que desejam comercializar produtos com diferencial ambiental.

A percepção do consumidor nem sempre é a mais correta, diz Polonsky (1994), e precisa ser mudada. Embora admita-se que as organizações empresariais, em geral, devem assumir grande parte da responsabilidade relativa à degradação ambiental, mas não exclusivamente, porque é o consumidor quem demanda os produtos que criam problemas ambientais, é este quem decide como e onde usar, e como e onde despejar o lixo.

\section{Comunicação e educação ambiental}

De acordo com as pesquisas sobre comportamento dos consumidores, as estratégias de marketing, para serem bem sucedidas, devem adequar-se às contingências ambientais influenciadas pelas preferências dos consumidores (Engel; Blackwell; Miniard, 1993, p. 640). Ao se presumir que “(...) os consumidores sabem o que querem", procura-se ofertar o que as pesquisas de mercado apontam sobre as preferências no mercado, o que faz com que empresas concorrentes tendam a abordar o mercado com estratégias semelhantes, reduzindo a variedade de diferenciações disponibilizadas para consumo. No entanto, sugere Carpenter (2001, p. 7-11), o marketing deve basear-se no pressuposto de que, “(...) pelo menos no início, os clientes não sabem o que querem, mas aprendem o que querem”. Suas percepções e preferências são resultado do processo de aprendizagem proveniente da circulação de informações, que faz com que as oportunidades no mercado evoluam à medida que os consumidores aprendam. Dessa forma, para se obter sucesso com a diferenciação ambiental, é preciso que haja uma nova dimensão do produto ou serviço, cujo valor os consumidores possam aprender. Concebido dessa forma, o marketing é um processo de aprendizagem e ensino, com o objetivo de "(...) influenciar a evolução das percepções" dos consumidores, criando diferenciações perceptivas que não possam ser imitadas pelos concorrentes.

Para o marketing verde, a questão central, então, é a educação ambiental. Ela se constitui no instrumento essencial durante o processo de tornar os cidadãos mais atentos às conseqüências de seus comportamentos em relação à natureza e à sociedade. Trabalho de longo prazo, a educação ambiental de sucessivas gerações promove as mudanças culturais e sociais necessárias à predominância da ética 
ecológica. O escopo dessa educação deve ser a transformação da forma como as pessoas percebem o mundo e a relação de causa e efeito entre seus hábitos de consumo e a qualidade do meio ambiente. Com a evolução da percepção, espera-se que as pessoas mudem seus comportamentos sociais e seus modelos de tomada de decisão sobre o que consumir. Uma vez iniciado o processo, é plausível acreditar que as oportunidades para produtos ecológicos crescerão à medida que as novas gerações sejam educadas sobre ecologia e a preocupação ambiental se incorpore ao estilo de vida de um número crescente de consumidores, pois, como diz Ottman (1998), “(...) a mind once expanded never goes back to where it was' ('...a mente uma vez esclarecida nunca retorna ao ponto de partida").

Uma forma eficaz de as organizações empresariais contribuírem com o processo de educar ambientalmente os consumidores e colaboradores é através do compromisso de informar a comunidade sobre assuntos complexos em linguagem acessível ao grande público. Expor a verdade sobre os problemas ambientais é o mais recomendável, afirma Donaire (1995). Diante da crescente angústia social devido ao agravamento dos problemas ambientais, “(...) comunicar, explicar e convencer tornou-se tão importante quanto fazer, produzir e realizar", pois o perigo pode ser contornado por um sistema de segurança, mas “(...) a angústia só pode ser controlada através da comunicação” (Backer, 1995, p. 76). A boa comunicação com a comunidade ameniza o impacto negativo que possíveis problemas ambientais causados pelas operações da organização possam causar e reduz o risco de a organização ser percebida como grande poluidora. Dentro desta lógica, recomenda-se às organizações compartilhar a solução de problemas ambientais com a comunidade, além de patrocinar projetos comunitários de grande visibilidade junto ao público consumidor.

Para Callenbach et al. (1999), a publicidade dos produtos "verdes" deve enfatizar a satisfação duradoura do comprador, a atratividade do custo em relação ao tempo de vida do produto, a competitividade em termos de confiabilidade e ausência de problemas, as possibilidades de reutilização e/ou de reciclagem dos produtos e seus invólucros, o baixo impacto ecológico da manufatura, distribuição, uso e descarte dos produtos. Ou seja, enfatizar as vantagens ao longo de todo o ciclo de vida do produto (produção, uso e descarte), e não apenas a excitação do impulso na hora da compra.

A comunicação dos princípios e práticas internas da organização é recomendada por Jöhr (1994) para mostrar ao público em geral as ações e os resultados alcançados. Isso tem o objetivo de reforçar a educação ambiental dos funcionários e dos consumidores, estimular práticas ecológicas na sociedade e consolidar uma imagem pública favorável à empresa para a eventualidade de alguma disputa judicial envolvendo problemas ambientais.

\section{Marketing florestal madeireiro}

O marketing de diferenciação ambiental de produtos passou a ser estrategicamente fundamental para o setor florestal, em especial para o setor madeireiro. Os produtos da madeira concorrem em um mercado com ampla variedade de materiais substitutos, que inclui produtos de metais ferrosos e não ferrosos, produtos de minerais não-metálicos e produtos petroquímicos. De maneira geral, ao se comparar os dados quantitativos resultantes da análise do ciclo de vida, qualquer produto apresenta alguma vantagem ambiental, por isso, dependendo das variáveis utilidade técnica e preço, há demanda de mercado para uma ampla combinação de materiais e produtos.

A utilidade técnica e o preço são apontados por Meil (1994) como os principais fatores de influência na decisão de substituir produtos da madeira por produtos de outros materiais. Como o processo de escolha de produtos, sob a influência dos novos conhecimentos científicos sobre o meio ambiente, das pressões dos ambientalistas e das regulamentações governamentais, vem evoluindo no sentido de incluir os benefícios ambientais na composição da demanda, os produtos da madeira possuem condições privilegiadas para explorar o marketing de diferenciação ambiental e reverter parcialmente a tendência de substituição verificada nas últimas décadas. Se o sistema de preços praticado no mercado refletisse os custos dos impactos ambientais associados à produção de bens, os produtos florestais ampliariam ainda mais suas vantagens competitivas frente aos produtos substitutos.

Embora as vantagens ambientais dos produtos florestais sejam evidentes em relação a seus potenciais substitutos, a vantagem competitiva do setor depende, de acordo com Hartikainen (1994, p. 188), de “(...) bom senso no manejo das florestas, sensibilidade na colheita, controle técnico no processo de industrialização e responsabilidade social nas atividades de marketing". Segundo o autor, o desenvolvimento dos mercados de produtos florestais tende a ser norteado pelo confronto entre o 
paradigma de utilização convencional das florestas e o paradigma de desenvolvimento sustentável, de forma que os aspectos sociais da sustentabilidade ambiental afetem cada vez mais as decisões de consumo, independentemente das variações na demanda decorrentes do crescimento demográfico e das flutuações econômicas.

Para Auchincloss (1994), a globalização da economia vem fazendo com que o planejamento estratégico no setor florestal oriente-se para o mercado, mudando o foco para atender demandas de mercado, em substituição ao foco na oferta de produtos. Devido a isso, intensificaram-se os investimentos em pesquisa e desenvolvimento de tecnologias que maximizam o aproveitamento dos recursos naturais, gerando, em conseqüência, produtos com alto valor agregado que permitem recuperar no mercado as inversões de capital em inovações.

\section{Estudo de caso: marketing madeireiro no Canadá}

Conforme dados de 2003 divulgados pela Food and Agriculture Organization of the United Nations (FAO), o Canadá é o país com a terceira maior área de floresta no planeta (245 milhões de ha), menor apenas que Rússia e Brasil (851 e 544 milhões de ha, respectivamente). As florestas canadenses, abrigando cento e oitenta espécies de árvores, representam mais de dez por cento da área florestal mundial e metade delas estão disponíveis para exploração. São cortados aproximadamente um milhão de hectares por ano, dos quais cinqüenta e três por cento regeneram-se naturalmente, quarenta e três por cento são replantados e quatro por cento são recuperados com plantio direto (FAO, 2005). A área com cobertura florestal atualmente existente no Canadá equivale a $90 \%$ da área com cobertura florestal existente no país antes do início da colonização européia, de acordo com informação do Canadian Wood Council (CWC) e da Forest Products Association of Canada (FPAC) (CWC/FPAC, 2002). A produção do setor florestal representa 3\% do PIB canadense, com exportação anual de 40 bilhões de dólares (madeira, celulose e papel), gerando mais de 900 mil empregos diretos e indiretos (FPAC, 2005). Para o futuro, o setor avalia que dispõe de matéria-prima, tecnologia e capacidade produtiva sustentável para aumentar a oferta de produtos madeireiros sem reduzir a área total de florestas.

No mercado da construção civil, porém, o setor enfrenta acirrada concorrência da indústria de materiais substitutos (aço, cimento, plástico). Em busca de soluções para superar as limitações de mercado impostas pela concorrência e pelas novas regulamentações ambientais, há mais de dez anos um consórcio de parceria público-privada iniciou o patrocínio de pesquisas comparativas sobre os impactos ambientais ao longo do ciclo de vida dos materiais substitutos mais utilizados (madeira, aço e cimento) em estruturas de edificações residenciais e comerciais (Meil, 1994). Os resultados das pesquisas mostram os valores do impacto ambiental de cada material desde a extração até a destinação final após o período de utilização.

Passada mais de uma década desde o início das pesquisas, as instituições e empresas representativas do setor florestal empreenderam uma ofensiva de marketing com base na diferenciação ambiental, divulgando os resultados das pesquisas, enfatizando as vantagens da madeira sobre outros materiais substitutos na construção civil e ensinando a utilizar os produtos disponíveis no mercado. As iniciativas de marketing visam informar e estimular os profissionais que especificam os produtos nos projetos de construção (construtores, arquitetos, projetistas, decoradores, proprietários) a adotar projetos arquitetônicos de mínimo impacto (green design).

Para reforçar junto ao público em geral a percepção de que os produtos da madeira são ambientalmente recomendáveis e de que os empresários do setor estão comprometidos com a sustentabilidade ambiental das florestas e do planeta, o setor de produtos florestais canadense, no período entre 1990 e 2004, reduziu $28 \%$ da emissão de gases do efeito estufa e aumentou a produtividade em mais de 30\%. Tal desempenho ultrapassa em mais de quatro vezes as metas do Protocolo de Kyoto. Em adição a isso, o setor comprometeu-se com o governo do Canadá a reduzir em 15\% a emissão de gases do efeito estufa até 2010 (FPAC, 2005).

A certificação de manejo florestal sustentável é outro componente importante da estratégia de marketing de diferenciação ambiental do setor madeireiro canadense. Trinta e oito por cento da sua área florestal (93 milhões de ha) possui algum tipo de certificação de manejo sustentável concedido por auditoria independente e internacionalmente reconhecida (CWC/FPAC, 2002).

A estratégia de marketing de diferenciação ambiental do setor madeireiro canadense, portanto, apresenta três características importantes: 1) pesquisa científica e desenvolvimento de produtos; 2) 
certificação de manejo sustentável de florestas; e 3) comunicação educativa sobre os produtos.

\section{Pesquisa cientifica e desenvolvimento de produtos}

A avaliação do Ciclo de Vida (Life-Cycle Assessment - LCA) é um método analítico que segue as diretrizes da ISO série 14001 e afere quantitativamente as seguintes variáveis: energia primária consumida, potencial de aquecimento global, poluição do ar e da água, quantidade de matéria-prima usada e dejetos sólidos gerados em cada etapa do ciclo de vida do produto (CWC, 2004). Ou seja, ele mede o impacto ambiental de todos os produtos, processos ou atividades desenvolvidas desde a extração e processamento de matéria-prima até a industrialização, transporte e distribuição, uso, manutenção, reciclagem e deposição final dos materiais. A quantificação possibilita que sejam feitas comparações entre produtos substitutos, auxiliando na tomada de decisões sobre materiais e produtos a serem utilizados em edificações (CWC/FPAC, 2002). Através da LCA, é possível avaliar os méritos ambientais de produtos e processos quanto à poluição do ar, toxidade ecológica, depleção de combustível fóssil, alteração de hábitats, saúde humana, qualidade do ar interior em residências e locais de trabalho, depleção da camada de ozônio, consumo de água, etc.

$\mathrm{Na}$ comparação entre edificações similares construídas com estruturas de materiais diferentes, (madeira, concreto e aço), as pesquisas canadenses mostraram que as edificações em aço e concreto embutem $26 \%$ e $57 \%$ mais energia; emitem $34 \%$ e $81 \%$ mais gases de efeito estufa; liberam $24 \%$ e $47 \%$ mais poluentes no ar; despejam 4 e 3,5 vezes mais poluentes na água; usam $11 \%$ e $81 \%$ mais matériaprima em peso; e produzem $8 \%$ e $23 \%$ mais dejetos sólidos, respectivamente, do que as edificações em madeira (CWC, 2004).

Quanto à manutenção e operacionalização de cada edificação em um prazo de 20 anos de uso, a edificação em aço consome 5\% mais energia primária; emite 5\% mais gases de efeito estufa; emite $6 \%$ mais poluentes no ar; despeja $6 \%$ mais poluentes na água; usa $1 \%$ mais recursos em peso; e produz $3 \%$ mais dejetos sólidos do que a edificação em madeira. A construção em concreto consome $1 \%$ menos energia primária e apresenta resultados semelhantes à madeira quanto às outras variáveis (CWC, 2004).

O efeito ambiental total, calculado através da soma entre efeitos ambientais embutidos e efeitos ambientais de manutenção, mostra que, em um período de uso de vinte anos, as edificações em aço e as edificações em concreto embutem e consomem $12 \%$ e $20 \%$ mais energia; emitem $15 \%$ e $29 \%$ mais gases de efeito estufa; emitem $10 \%$ e $12 \%$ mais poluição no ar; despejam 3 e 2,25 vezes mais poluentes na água; usam $7 \%$ e $50 \%$ mais recursos em peso; e produzem $6 \%$ e $16 \%$ mais dejetos sólidos, respectivamente, quando comparadas às edificações em madeira (CWC, 2004). Ou seja, a redução de custos ambientais na casa de madeira é equivalente a dois anos e meio de energia operacional e três anos e meio de emissão de gases que causam aquecimento global, em comparação ao uso do aço; e é equivalente a cinco anos e meio de energia operacional e oito anos e meio de emissão de gases que causam aquecimento global, em comparação ao uso do concreto.

As principais limitações legais ao uso da madeira em alguns tipos de construções se referem principalmente aos aspectos acústico e vulnerabilidade ao fogo. Outro aspecto é o limite de resistência aos esforços de tração e cisalhamento (Timber Bulletin, 2004). Diante de tais limitações, o desafio tecnológico passou a ser o desenvolvimento de produtos de madeira com bom desempenho em relação aos fatores limitantes.

Para enfrentar tal desafio, o setor florestal canadense investiu em tecnologia digital, no desenvolvimento de produtos com alto valor agregado e no aperfeiçoamento dos processos de colheita, industrialização, construção e manutenção de edifícios (CWC, 2005a). Pesquisadores e executivos do setor acreditam que a dependência em novas tecnologias e novos conhecimentos tende a aumentar, incrementando a diversificação de produtos com alto valor agregado (Forintek, 2003).

\section{Certificação florestal}

Os programas de certificação florestal e selos de classificação destinam-se a reconhecer oficialmente as empresas e proprietários de terra que voluntariamente manejam as florestas de forma sustentável, seguindo critérios pré-definidos. Devido à tendência de aumento na demanda por benefícios ambientais, cresce a utilização da certificação de manejo sustentável de florestas, com o objetivo de dirimir as dúvidas sobre a origem da matéria-prima e reforçar no público a percepção de que os produtos ofertados embutem valor ambiental real (CWC, 2005b). A certificação de manejo florestal sustentável 
também ajuda a conseguir acesso a mercados específicos, justifica a cobrança de valor-prêmio sobre o preço dos produtos e previne publicidade negativa por parte dos ativistas ambientais (Cashore; Auld; Newsom, 2004).

No Canadá, de acordo com dados do CWC (2005b), a procura por certificação triplicou nos últimos dois anos, totalizando 86,5 milhões de hectares certificados ao final de 2004, dos quais 47,4 milhões de hectares (54\%) certificados pela Canadian Standard Association (CSA), 35,5 milhões de hectares (41\%) certificados pela Sustainable Forestry Initiative (SFI) e 4,4 milhões de hectares (5\%) certificados pelo Forest Stewardship Council (FSC).

A idéia de certificação surgiu por iniciativa de "instituições não-estatais orientadas para o mercado" (non-state market-driven institutions), com o objetivo de promover o desenvolvimento sustentável fora dos processos governamentais usuais (Cashore; Auld; Newsom, 2004). Ou seja, as certificações utilizadas no setor florestal são sistemas privados destinados à governança de um bem público: a qualidade do meio ambiente. Os fatores conjunturais que sedimentaram as condições para o surgimento das certificações florestais foram, de acordo com Cashore, Auld e Newsom (2004), a globalização do comércio internacional, a incapacidade dos governos nacionais em atender as demandas ambientais dos grupos de pressão e a falta de acordo durante a Eco-92, no Rio de Janeiro, para a assinatura da Convenção Global das Florestas.

Frente às incertezas suscitadas pelo impasse na negociação da Convenção das Florestas, instituições ambientalistas globais lideradas pelo World Wild Fund for Nature (WWF) criaram, em 1993, o Forest Stewardship Council (FSC), a primeira instituição de auditoria e certificação florestal em nível mundial. Em resposta, grupos empresariais e proprietários florestais privados dos Estados Unidos, através da American Forest and Paper Association (AF\&PA) lançaram, em 1994, a instituição de certificação florestal Sustainable Forestry Initiative (SFI) (Cashore; Auld; Newsom, 2004).

No Canadá, o processo para desenvolver os padrões de gestão sustentável de florestas (Sustainable Forest Management - SFM) começou em 1993, com a formação da Canadian Sustainable Forestry Certification Coalition (CSFC), um grupo representando vinte e duas associações empresariais do setor florestal, que em 1994 solicitou à Canadian Standards Association (CSA) a elaboração de normas técnicas para o manejo sustentável de florestas (SFM) no Canadá. Em 1996, a CSA apresentou um sistema de certificação inspirado no SFI e na ISO 14001, denominado Standard CAN/CSA-Z809-96. O sistema do CSA foi revisado em 2000 e um novo padrão (Standard CAN/CSA-Z809-02) entrou em vigor em dezembro de 2002 (Form International, 2004). O sistema de normas ISO 14001 (Environment Management System) é um padrão internacional aprovado pela International Standardization Organization em 1996, cuja referência específica à área florestal é feita no informativo técnico ISO 14061 (Technical Report to Assist Forestry Organizations in the Use of ISO 14001).

De maneira geral, os sistemas de certificação florestal que surgiram por iniciativa de instituições empresariais tendem a ser mais flexíveis e mais genéricos do que o programa de certificação do FSC. Ao longo do tempo, porém, eles foram sendo modificados com tendência a convergirem entre si, porque sua autoridade e legitimidade dependem da capacidade de cada um em convencer o maior número de empresas e proprietários de terra a adotá-los. A principal divergência entre eles está no fato de o FSC priorizar as variáveis ambientais e sociais junto com os processos naturais, enquanto que os esquemas empresariais priorizam as práticas e operações florestais permitindo exploração mais intensiva da floresta. O sistema padrão ISO é um caso à parte nessa disputa de mercado, porque é um padrão criado por representantes das associações nacionais de normas técnicas dos países membros e, embora adotado para certificação florestal, seu objetivo é mais abrangente quanto à gestão dos recursos ambientais, apresentando por isso dispositivos mais genéricos.

No período de uma década de existência dos principais sistemas de certificação florestal, houve ocorrência de iniciativas em busca de mútuo reconhecimento, como é o caso do International Mutual Recognition Framework for Forest Certification, baseado nos conceitos de reciprocidade, nãodiscriminação e equivalência (IFIR, 2001), proposto pelo International Forest Industry Roundtable (IFIR), uma rede global de associações nacionais e companhias multinacionais. Por outro lado, Organizações Não-Governamentais (ONGs) que apóiam o SFC opõem-se ao reconhecimento mútuo sob o principal argumento de que isso nivelaria por baixo os padrões de certificação (Forest Certification and Mutual Recognition, 2001). Os últimos desenvolvimentos desse processo apontam para a tendência de os principais sistemas de certificação, à exceção do FSC, convergirem para o mútuo reconhecimento sob o 
sistema PEFC (Programme for the Endorsement of Forest Certification Schemes), antes conhecido como Pan European Forest Certification System), como é o caso do SFI e do CSA, que em 2004 solicitaram endosso de conformidade ao PEFC (Fernholz, 2005).

\section{Comunicação educativa}

A utilização do marketing de diferenciação ambiental ocorre num contexto em que as empresas conhecem melhor os clientes por utilizarem tecnologias mais interativas, e os clientes possuem maior poder de barganha por possuírem maior facilidade de acesso a informações. Mas o acesso à informação por parte dos consumidores precisa ser auxiliado pelas organizações que desejam promover seus produtos. Seguindo a idéia de que o marketing é um processo de educação do público sobre consumo, o setor florestal canadense criou o projeto Wood WORKS! (“TRABALHOS em Madeira!"), que promove educação para que os consumidores tenham orgulho por optar pela madeira, oferece treinamento e dá assistência técnica para que os usuários de madeira saibam como usá-la.

Wood WORKS! é uma campanha nacional que visa estimular o uso de madeira em construções comerciais, industriais e institucionais. Foi criado sob a liderança do Canadian Wood Council (CWC) para promover os benefícios ambientais do uso da madeira e aumentar seu mercado no longo prazo. As atividades são financiadas por empresas do setor madeireiro e pelo governo canadense. Seu objetivo é desenvolver um movimento cultural que valorize a madeira como a primeira opção em projetos de construção, a fim de consolidar o Canadá como líder mundial em edificações em madeira. Para atingir seus objetivos, utiliza propaganda, eventos, relações públicas, mídia gratuita (artigos, entrevistas, reportagens, etc.) e outros instrumentos de marketing ao seu alcance.

Dentre as ações de marketing, destacam-se: realização de feiras (Wood Solutions Fairs - Feira de Soluções em Madeira), oferta gratuita de serviços (websites e telefones do tipo 0800), premiação de iniciativas exemplares (Wood WORKS! Awards Gala - festividade de premiação para projetos com madeira), estímulo à troca de experiências (Wood Champions Network - rede de relações entre usuários de madeira) e pesquisa de mercado. O CWC também desenvolveu, e disponibiliza gratuitamente, um software para ajudar os projetistas a acessar de forma rápida o código de obras da construção civil canadense e saber quais especificações técnicas são requeridas para uso da madeira.

A Wood Solutions Fairs, realizado em várias cidades do Canadá e dos Estados Unidos, é uma feira educacional sobre construção com madeira, dirigida aos profissionais responsáveis pelas decisões nos projetos de construção, para mostrar os produtos ofertados e como eles podem ser utilizados. A Wood WORKS! Awards Gala é um evento para premiar pessoas e organizações que desenvolvem projetos significativos que ajudam a preservar a cultura de uso da madeira na construção civil. A Wood Champions Network é um site (<http://www.woodchampions.com $>)$ para conexão entre especialistas, líderes, administradores e entusiastas por madeira (CWC, 2005c).

Além das iniciativas em âmbito nacional, o setor florestal canadense articulou junto com o setor florestal dos Estados Unidos a Wood Promotion Network (WPN - Rede de Promoção da Madeira), para promover o mercado de madeira da América do Norte. A WPN é uma coalizão empresarial criada em 2000, resultante de uma iniciativa co-liderada pelo Canadian Wood Council, que começou em 1998 com o nome "Wood Is Good" ("Madeira É Bom"). Seu objetivo é contrapor-se às campanhas que associam os produtos da madeira ao desmatamento e à depleção ambiental e enfrentar a concorrência de produtos feitos com materiais substitutos à madeira. Suas atividades são financiadas por empresas e entidades de classe do setor madeireiro. Atualmente, a WPN conta com 243 empresas e 97 associações filiadas, que representam mais de dois terços da produção madeireira da América do Norte. Sua principal missão é educar construtores, revendedores e consumidores sobre a superioridade da madeira como material de construção e sobre sua característica natural como recurso renovável (WPN, 2005). Entre suas atividades estão: International Builders' Show (Feira Internacional de Construtores - a maior feira da construção civil na América do Norte), Wood Information Bureau (Central de Informação da Madeira - uma central de relações com a mídia para subsidiar reportagens e artigos sobre o uso da madeira), websites (<www.woodpromotion.net>, <www.beconstructive.com>, <www.forestinformation.com $>$ ), campanhas publicitárias e pesquisas de mercado.

A estratégia de comunicação desenvolvida é centrada em um processo educacional sobre o uso adequado da madeira e é impulsionada por uma ofensiva publicitária informando as vantagens do uso da madeira devido às suas características naturais de utilizar a energia do sol para renovar-se em um ciclo de 
sustentabilidade contínua, seqüestrar e estocar carbono retirado da atmosfera, ser reutilizável, reciclável e biodegradável, moderar a umidade em ambientes internos, ser isolante térmico natural (com índice de condutividade de calor 400 vezes menor que o do aço) e possuir resíduos que podem ser transformados em produtos de alto desempenho para variadas aplicações ou serem utilizados como biocombustível.

Pesquisa de mercado realizada pela Wood Promotion Network mostra que o número de consumidores na América do Norte que acreditam que a madeira é um material de construção melhor do que o concreto ou o aço cresceu de $22 \%$ para $70 \%$; e o número de construtores que percebem que a popularidade da madeira está crescendo passou de $15 \%$ para $53 \%$ (WPN, 2005).

\section{CONCLUSÃO}

Diante do crescimento das expectativas e demandas por iniciativas de proteção ambiental a identificação e supressão de possíveis riscos ambientais devidos às atividades organizacionais, bem como a procura de oportunidades para criar valor com tais atitudes constituem-se em ação primordial para a administração estratégica das organizações.

Por serem de interesse público, as questões ambientais tendem a ser regulamentadas pelo governo a fim de motivar as pessoas, tanto físicas quanto jurídicas, a mudarem seus hábitos de consumo e assumirem maior responsabilidade ambiental. Como alguns comportamentos humanos não são facilmente influenciáveis, exigindo longo prazo para se processarem as mudanças, e como há catástrofes naturais imprevisíveis ou fora do escopo das regulamentações, verificam-se externalidades que elevam os gastos com desenvolvimento tecnológico para compensar os desequilíbrios ambientais causados pelas atividades humanas. Por conseguinte, para as organizações empresariais, normalmente, as regulamentações governamentais representam a internalização das externalidades ambientais na forma de aumento de custos operacionais, independentemente de eles poderem ser incorporados no valor de mercado dos bens produzidos. Sendo assim, no processo de internalização das externalidades ambientais aplica-se a "Lei dos Rendimentos Decrescentes" em relação aos investimentos em qualidade ambiental, devido à incorporação como custo do valor social agregado dos recursos usados na produção.

Como a maior parte dos acréscimos de qualidade ambiental em um processo, produto ou serviço apresenta o custo de oportunidade, uma questão chave para as organizações empresariais dispostas a fornecê-la é adquirir capacidade para captar no mercado os acréscimos de custos, se houver, sendo capaz também de captar o diferencial de valor que a diferenciação ambiental pode gerar. Há, porém, algumas medidas que resultam em melhor desempenho ambiental com redução de custos operacionais (custos negativos), como, por exemplo, o reaproveitamento de resíduos e efluentes ou os programas de racionalização no uso de matérias-primas e energia. Considerando as previsões das necessidades humanas futuras, os custos futuros totais precisam ser incorporados ao planejamento ambiental, ao qual se aplica a "Lei dos Custos Sociais Crescentes" diante das alternativas de uso dos recursos disponíveis.

A opção pelo marketing de diferenciação ambiental parece ser a estratégia que apresenta a melhor perspectiva de recuperar no mercado os custos gerados pela gestão dos riscos ambientais. Um pressuposto básico para o conceito de diferenciação ambiental de produtos é o de que as organizações empresariais podem obter lucros ao investir em qualidade ambiental, seja porque consomem menos recursos, seja porque incorporam no preço o valor da qualidade ambiental, ou ainda porque podem criar condições de mercado que permitam produção com ganho de escala. Desenvolver processos, produtos ou serviços que oferecem maior benefício ambiental ou que infligem menor custo ambiental do que os produtos substitutos é a essência do marketing de diferenciação ambiental. Embora a introdução dos benefícios ambientais possa elevar os custos operacionais, também propicia oportunidades para a cobrança de preços com maior percentual de lucro ou permite conquistar maior percentual de mercado.

A utilização da estratégia de diferenciação ambiental para um posicionamento competitivo no mercado exige que os riscos e oportunidades relacionados às questões ambientais sejam abordados sob a perspectiva de longo prazo. No curto prazo, ela se insere num contexto em que as empresas conhecem melhor os clientes, solicitam sua integração ao desenvolvimento de novos produtos, comunicam-se com eles utilizando tecnologias mais interativas e as condições de oferta dos produtos são flexibilizadas para fornecer aos clientes maior valor agregado. Como as tecnologias tornam-se rapidamente acessíveis aos concorrentes, permitindo que copiem vantagens e abreviem etapas para o desenvolvimento de novos produtos, a vantagem competitiva mais sustentável é a rapidez em aprender com as mudanças, mudar e 
influenciar novas mudanças. Principalmente influenciar os consumidores a incorporar valores ecológicos nos hábitos de consumo, através de campanhas que educam o público ao mesmo tempo em que promovem produtos "verdes".

O compromisso com a qualidade do meio ambiente representa um importante fator na definição e implementação do marketing de diferenciação ambiental. Como há predominância do padrão de consumo sobre o padrão de produção, os hábitos de consumo e estilo de vida dos consumidores moldam os padrões produtivos. Atender as expectativas e necessidades dos consumidores, tanto as de utilidade e conveniência (individuais) quanto as intangíveis e não-comerciais, reforça o marketing de diferenciação ambiental como uma atitude de responsabilidade social. Tal responsabilidade social está presente não apenas em responsabilizar-se pelo custo da poluição, mas também em suprir os consumidores com informações que os auxiliem a tomar decisões mais racionais quanto à sustentabilidade ambiental, em um processo contínuo de educação para o consumo.

Devido às características naturais dos produtos florestais, as empresas do setor possuem condições privilegiadas para auferir vantagens competitivas estratégicas ao adotar o marketing de diferenciação ambiental. O setor florestal pode, assim, assumir sua responsabilidade social pelo desenvolvimento sustentável e ao mesmo tempo beneficiar-se dos efeitos mercadológicas que tal estratégia pode proporcionar.

\section{REFERÊNCIAS}

AUCHINCLOSS, P. S. Understanding customer needs: a requirement for winning and keeping customers world wide. In: FOREST PRODUCTS SOCIETY. The globalization of wood: supply, processes, products, and markets. Madison, WI: FPS, 1994, p.153-161.

BACKER, P. Gestão ambiental: a administração verde. Rio de Janeiro: Qualitymark, 1995.

CALLENBACH et al. Gerenciamento ecológico: guia do Instituto Elmwood de auditoria ecológica e negócios sustentáveis. 9. ed. São Paulo: Cultrix, 1999.

CANADIAN WOOD COUNCIL. Energy and the environment in residential construction. 2004, Sustainable Building Series, n.1. disponível em: <http://www.cwc.ca> acesso em 28.mar.2005.

Value-added wood products. Ottawa: Sustainable Building Series n.9. disponível em: $<$ http://www.cwc.ca $>$, acesso em 28.mar.2005a.

Certified wood products. Ottawa: CWC, 2005b, Quick Facts Sustainable Building Series n. 10. PDF disponível em www.cwc.ca>, acesso em 28.mar.2005b.

$\overline{03 . a b r .2005 c}$

What is Wood WORKS! Disponível em: <http://www.wood-works.org>, acesso em

CANADIAN WOOD COUNCIL; FOREST PRODUCTS ASSOCIATION OF CANADA. Green by Design: renewable, durable, sustainable wood. 2002. disponível em $<<$ http://www.fpac.ca $>$, acessado em 28.mar.2005.

CARPENTER, G. S. Mudando as regras do jogo de marketing. In: FINANCIAL TIMES. Dominando o marketing. São Paulo: Makron, 2001, p.7-11.

CASHORE, B.; AULD, G.; NEWSOM, D. Governing through markets: forest certification and the emergence of non-state authority. New Haven: Yale University, 2004. disponível em: $<$ http://www.governingthroughmarkets.com>, acesso em 04.abr.2005.

CORDEIRO, J. V. B. M. Reflexões sobre a Gestão da Qualidade Total: fim de mais um modismo ou incorporação do conceito por meio de novas ferramentas de gestão? In: REVISTA FAE, Curitiba, v.7, n.1, p.19-33, jan./jun. 2004.

DEMING, W. E. Some theory of sampling. New York: John Wiley and Sons, 1950.

DONAIRE, D. Gestão ambiental na empresa. São Paulo: Atlas, 1995.

EDMUNDS, S.; LETEY, J. Ordenación y gestión del medio ambiente. Madrid: IEAL, 1975. 
ENGEL, J. F.; BLACKWELL, R. D.; MINIARD, P. W. Consumer behavior. 7.ed. Fort Worth, TX: Dryden, 1993.

FERNHOLZ, K.; et al. Beginner's guide to third-party forest certification: shining a light on the Canadian Standards Association (CSA). Disponível em: < http://www.dovetailinc.org $>$, acesso em 15.mai.2005.

FAO. Forestry Department country profiles. Disponível em: $<$ http://www.fao.org/forestry $>$, acesso em 14.mai.2005.

FOREST PRODUCTS ASSOCIATION OF CANADA. Forest products industry takes leadership role on climate change. disponível em: $<$ http://www.fpac.ca>, acesso em 22.mar.2005.

FOREST CERTIFICATION AND MUTUAL RECOGNITION: THE FUNDAMENTALS. Joint NGO statement on Mutual Recognition presented at the FAO-GTZ-ITTO Conference on 'Confidence Building Between Different Certification Schemes'. Rome, 19/02/2001. Disponível em: $<$ http://www.fern.org>, acesso em 15.mai.2005.

FORINTEK CANADA CORP. Technology Roadmap: lumber and value-added wood products. disponível em: $<$ http://www.forintek.ca>, acesso em 25.mar.2005.

FORM INTERNATIONAL. Report PEFC conformity assessment of the PEFC Canada Sustainable Forest Management Program. disponível em <http://www.pefc.org>, acesso em 15.mai.2005.

HARTIKAINEN, T. Future trends for Scandinavian wood products. In: FOREST PRODUCTS SOCIETY. The globalization of wood: supply, processes, products, and markets. Madison: FPS, 1994, p.188-194.

HOOLEY, G. J.; SAUNDERS, J. A.; PIERCY, N. F. Estratégia de marketing e posicionamento competitivo. 2. ed. São Paulo: Prentice Hall, 2001.

INTERNATIONAL FOREST INDUSTRY ROUNDTABLE. Proposing an international mutual recognition framework: report of the Working Group on mutual recognition between credible sustainable forest management certification systems and standards. disponível em: $<$ http://www.sfcw.org/mutualrecognition>, acesso em 11.mai.2005.

JÖHR, H. O verde é negócio. 3a. ed. São Paulo: Saraiva, 1994.

KOTLER, P. Para onde vamos? In: FINANCIAL TIMES. Dominando o marketing. São Paulo: Makron, 2001, p.5-6.

. Marketing management. 9.ed. Upper Saddle River, NJ: Prentice Hall, 1997.

LOVELOCK, C. Product plus: produto + serviço = vantagem competitiva. São Paulo: Makron, 1995.

MEIL, J. K. Environmental measures as substitution criteria for wood and non-wood building products. In: FOREST PRODUCTS SOCIETY. The globalization of wood: supply, processes, products, and markets. Madison: 1994, p.53-60.

OTTMAN, J. A. Green marketing: opportunity for innovation. On-line ed. New York: NTC-McGrawHill, 1998. Disponível em: <www.greenmarketing.com/green_marketing_book>. acesso em 07.jul.2003. $\overline{\text { Makron, } 1994}$

Marketing verde: desafios e oportunidades para a nova era do marketing. São Paulo:

POLONSKY, M. J. An introduction to green marketing. In: Electronic Green Journal, ISSN: 10767975, v. 1, n. 2, nov/1994. Disponível em: <http:gopher.uidaho.edu/1/UI_gopher/library/egj>. acesso em 8.out.2003.

REINHARDT, F. L. Down to earth: applying business principles to environmental management. Boston: Harvard, 1999.

SAUNDERS, T.; McGOVERN, L. The bottom line of green is black. 10.ed. New York: HarperCollins, 1997. 
SCHMIDHEINY, S. Changing course: a global business perspective on development and the environment. Cambridge, Ma: MIT, 1992.

TIMBER BULLETIN. UNECE / FAO forest products annual market review 2003-2004. Geneva: UN, v.57, n. 3, 2004.

WOOD PROMOTION NETWORK. Wood works: the WPN works for wood. Disponível em $<$ http://www.woodpromotion.net/home>, acesso em 21.mai.2005. 